\title{
"To secure a better future": the affordances and constraints of complex familial and social factors encoded in higher education students' narratives of engagement.
}

\author{
Vicki Trowler, Robert L. Allan and Rukhsana R. Din, University of \\ Huddersfield \\ Email: v.trowler@hud.ac.uk
}

\begin{abstract}
Not all students admitted to higher education have the same chances of success, with differential outcomes reported for students from a variety of "widening participation" backgrounds. This paper reports on a study of such students in a science foundation programme in the north of England. Analysing their stated motivations and aspirations for study reveals complex familial and social factors which enable and constrain their ability to engage with their studies. These notably include the duties and obligations towards their extended families that exist as a "kinship tax" and which threaten their ability to sustain sufficient time, energy and "headspace" to meet the demands of their studies. This presents challenges in teaching these students, whose priorities may not lie unambiguously with their studies, given their familial and social contexts.
\end{abstract}

Key words widening participation; differential outcomes; kinship tax; higher education

\section{Background}

Widening participation, defined as "redressing the under-representation of certain social groups in higher education" (Burke, 2012:12), has become a feature of higher education (HE) policy in recent decades, resulting in a shift in the demographic profile of the student body in many countries (Trowler 2019). Yet despite progress made in widening access, not all students who are admitted to HE have the same chances of success, with differential outcomes being reported by ethnicity (UUK / NUS 2019; McDuff et al., 2018), gender (Cotton et al., 2016), socio-economic status (Jones, 2018; Mowat, 2018) and commuter status (Southall et al., 2016), among other factors - this despite commuter students, and students from neighbourhoods where few people go on to higher education, showing greater levels of student engagement and more hours in both taught and independent study (Neves 2018). These disparities are not exclusive to HE, but persist from earlier education contexts, as noted elsewhere (Smith 2016) and continue beyond university, affecting employment prospects (Canning et al. 2018). 
This has led to an increased focus on student retention and success in research (Tight 2019 notes that these issues are among the most researched in $\mathrm{HE}$ in the previous four decades) and in policy and regulation, with e.g. the European Commission study (Quinn 2013) to inform policy in EU member states; some US states and parts of Australia linking state funding of universities to student retention and outcomes data (Harvey 2017) and the inclusion of student "continuation" data in the calculation of Teaching Excellence Framework data in the UK.

Within this context, a university in the north of England offers a foundation programme to students whose entry qualifications, skills or experience precludes their direct entry onto undergraduate programmes in the sciences. This year-long programme provides both content (in a wide range of science disciplines) and skills (discipline-related, as well as transferrable "softer" skills), as well as the opportunity to gain familiarity with the context of a university, to students - many of whom are the first in their families to participate in HE. The annual intake of over 100 students is diverse in terms of gender, age, ethnicity, nationality of origin, home language, educational and other background, but demonstrates a strongly local bias, with the majority of students commuting daily and living with family of origin, partners and/or children, or extended family in neighbouring communities. Most of the students on the programme display at least one - but usually more than one - factor identified earlier in relation to differential HE outcomes, yet are motivated to enrol in HE despite personal and structural obstacles.

This study aimed to explore how these students constructed their motivations for embarking on HE in the context of their lived experiences, how this enabled and constrained their engagement with their studies and how they mediated the tensions between their pre-arrival "identities" and their nascent "identities" orientated toward the "imagined communities" (Trowler,2019) encapsulated in these expressed motivations. This paper analyses the motivations for engaging in university studies reported by students in three successive cohorts of the programme, considering these within the daily lived contexts described by these students to understand how these students frame their studies, and how this may enable or constrain their progression through HE.

Understanding why and how these students came to HE, and the physical, emotional and conceptual paths they tread during their time on the programme, can inform the recalibration of practice at programme, School, and institutional levels, in the host context and other contexts where similar or analogous factors operate. Additionally, in providing nuanced texture of the lived experiences behind the broad brushstrokes of trend headlines, this paper illuminates the felt consequences of competing and contradictory policy thrusts among groups of students often positioned as "nontraditional", characterised via stereotypes but poorly understood through the 
intersection of multiple subjectivities and ascribed descriptors. As Clegg (2018:v) notes,

'... we need not just look at embedded structural constraints but... we should also consider how people understand their situation and their own abilities to act; hence the importance of narratives.'

The programme has a tradition of changing practices in response to learning about, and from, students, and stands out in defying the trend of differential outcomes based on ethnicity.

\section{Methods}

Students on the programme were informed of the study by the programme convenor at the beginning of each academic year, and were provided with information packs introducing the aim of the study and invitations to participate. In each cohort, students voluntarily provided informed consent and agreed to their data being used in the study. Such data included their results, the (pseudonymised) contents of written assignments, and data collected through survey and interview. This process was carried out at the start of the 2016-17 and 2017-18 academic years and later in the 2018-19 academic year, prospectively and retrospectively granting access to their data being used for the purposes of the study.

All students in the 2016-17 and 2017-18 cohorts were handed questionnaires in class, which all students in attendance on those days completed. Students in the 2018-19 cohort were introduced to the study at a session discussing progression into degree programmes later in the academic year which was not attended by all students, resulting in lower study recruitment rates. Students were informed that a purposive sample would be selected and approached for follow-up interview to explore emerging issues in greater depth. These interviews were conducted later in the academic year for each study cohort, when students were in a position to reflect back on their performance on the programme. During interviews students were asked about their reasons for enrolling, their study behaviours, their living arrangements, challenges they faced and related topics.

Participants were selected according to criteria including gender, ethnicity, age, prior qualifications, socio-economic background and commuter status, to ensure student populations identified in the literature as being"at risk" were adequately represented. These samples were limited by the availability of volunteers, as interviews were conducted outside of the academic year.

As part of their course requirements, students on each cohort were required to submit regular reflective blog posts on topics related to their 
motivations, study behaviours, intended destinations after completion of the programme and experiences of the programme. Students on the 2017-18 and 2018-19 cohorts were also required to submit brief videos using Adobe Spark, addressing their motivations and intentions. While these blog and video submissions were graded according to the academic requirements of the set assignments, they were also later analysed as data for this study.

In total 2354 blog posts and 346 Adobe Spark videos were analysed, along with 94 questionnaires and 22 interviews. Across the cohorts, 258 students participated in the research.

Data from questionnaires, interviews, blogs and videos were transcribed and analysed using NVivo, following a process similar to that described by Charmaz (2014:109-191) with initial coding of the data involving line-byline reading and highlighting of anything of note. Working through the data, similarities and differences between and within interviews were sought and more meaningful names were assigned to the initial codes. This initial coding was progressively augmented with focused coding, organising the codes into categories and teasing out relationships between these categories. This process was revisited a number of times, tweaking and adding codes as newer data pushed themes to the fore or backgrounded other codes, and concept maps were produced from the focused codes.

\section{Ethical Considerations}

Ethical approval was obtained through the appropriate School channels, and all research procedures conducted consistently with guidelines and good practice. All students voluntarily provided informed consent. They were informed of the purpose of the study, provided with information and the opportunity to ask questions, and were informed of their right to refuse consent or to withdraw it at any time (which would act retrospectively in the removal of their data from the study). Students approached for follow-up interview had a second opportunity to provide, or withdraw, informed consent. No student has withdrawn consent at the time of writing, from either current or previous cohorts.

The introduction of the study, and the issuing of invitations to participate and the associated collection of informed consent, within class time raises a potential ethical issue. The Principal Investigator for the study was the programme convenor during the initial two cohorts. While students were carefully informed that participation on the study was voluntary and would have no advantages or disadvantages for their studies, the possibility remains that some students may have considered it in their best interests academically to be seen to be cooperative. Survey questionnaires were handed out and completed during scheduled lectures, which may have led to further perceptions that student participation was strongly desired by the teaching team. 
In addition, follow-up interviews with the 2016-17 and 2017-18 cohorts were conducted by the course convenor at the time. While students who were approached for follow-up interview had the opportunity to decline and some did - it is still possible that some may have consented (whether consciously or otherwise) because they perceived the interviewer to be in a position of power over them, despite the academic year having ended. This may also have affected some of their responses, with some students possibly representing their study behaviours in the direction they considered would be welcomed by the interviewer. However, no qualitative differences were noted with the 2018-19 interviews, which were conducted by a researcher who was not part of the teaching team. Additionally, all analysis of questionnaire, interview and other data was carried out by this researcher, increasing sensitivity toward such possible influence over the data.

\section{Findings}

Students were asked explicitly in the survey questionnaires, the follow-up interviews, the blog assignments and the Spark video assignments, what their motivations were for choosing to attend university, and what they wanted to get from the experience. These responses form the basis for this paper, which considers these responses in the context of other data gleaned in response to other questions, as well as from other sources (such as basic demographic data submitted on enrolment). Several themes emerged from the data, with key themes clustering around the core idea of securing "a better future".

\section{Themes}

Students overwhelmingly stated that their prime motivation for embarking on the programme was "for a better future". This was disaggregated into economic ("to get a stable job") and cultural ("to gain respectability") components, with a significant number also noting that they wished "to help the community". Issues concerning how these students traverse and occupy space, and the relationships they maintain within these spaces, have been grouped together analytically as "spatial issues". These major themes from the data are considered in turn, below.

\section{Stable job}

The need to secure "a stable job" emerged as one of the most common motivations expressed by students in response to questions about their reasons for enrolling at university. This was common across student backgrounds, but appeared to take on a special significance among those students who cited experiences of observing closely the struggles of their parents: 
‘I want to get a good job so I won't struggle as much as my dad. ' (Student A)

'I have seen how hard [my parents] worked without a degree.' (Student B)

Many students were quite explicit about wishing to alleviate family financial struggles by providing monetary help, made possible by the envisaged surplus a secure job would provide.

'Getting a degree would allow ... being able to provide for my family so they may live comfortably.' (Student Z)

'I want to provide my kids with a better future... I want to secure a better future for my family.' (Student J)

Students' motivations in this regard, however, were not entirely altruistic. Several students cited observing their parents' circumstances and wanting something different for themselves as a motivating factor.

'Getting a degree would open more doors in my future career path and hopefully I will be more successful than my parents.' (Student R)

For these students, the capacity to afford "luxuries", to enjoy a lifestyle which allowed for a degree of hedonism, and which allowed them free time to pursue their own interests rather than working hard simply to survive, was appealing.

'...to give me the chance to take up a job that I have an interest in and which also pays me the right amount of money for the effort I put in, at present I can't afford to take my children on holiday, but with hard work and dedication that time will come.' (Student S)

'I need money to do the things I want to do.' (Student F)

Rather than merely reflecting materialistic orientations, these students expressed a consciousness of the structural disadvantages they faced through a lack of ready access to financial resources, similar to that observed by Lehmann (2009). This is further illuminated by their expressed aspirations:

'The honest most valuable reason of getting a degree is being able to find and be qualified for a higher paying job so they can live their lives with much more ease when it comes to paying for the expenses of lives [sic] luxuries... In this day and age money is everything... It allows ones future children to have a brighter future for themselves also as studies have shown children in higher income households generally tend to do better in school and therefore tend to get into higher paid jobs themselves.' (Student X)

'A degree, with the opportunity it brings, increases my chances of a higher salary, thus improving my quality of life, and increasing my ability to be an agent for change not simply for myself but for others too.' (Student $Q$ ) 
'Getting a degree... will put me in control of my future.' (Student V)

\section{Respectability}

Respectability emerged as a key theme, with several students stating that they wanted "a respectable degree", or to become "a respectable person in society". This was particularly prevalent among, but not unique to, students from communities with roots in south Asia. Obtaining a degree was seen as key to this aspiration:

'... obtaining a degree would turn me into a mature, wise, and a dominant person in the society ... my degree is going to make my parents proud and people respect me.' (Student T)

This was sometimes expressed in terms of "value" or "honour":

'[My motivation is] so that I would have a value in society.' (Student K)

'The primary advantage of a degree would be that I would qualify for a high quality, reputable job with a good income which will stabilise my future... It is also important to me as it would make me the first female in my family to achieve such an honourable qualification.' (Student N)

Other students expressed aspirations toward respectability in terms of status, even where they felt uncomfortable with such concerns:

'[Higher education] gives me more status in terms of qualifications and more leverage when looking for a job.' (Student $\mathrm{H}$ )

'For my parents, it's about status... Status is a big thing in Asian society, they care a lot. [Status affects] your marriage prospects: "You can marry who you want as long as they earn more than you." My mum really cares how they are perceived by society. [That makes me feel] very uncomfortable. My cousin married; no one likes her husband because he doesn't have a good job [or status].' (Student F)

Science, in particular, was considered to be a route to respectability, beyond the more widespread perception among most of the students of it offering a greater range of employment possibilities post-graduation. Again, this was noted to be particularly prevalent among students from communities with roots in Asia:

'Studying Science was influenced by my parents... It's common for Asian parents to focus on sciences.' (Student D)

For students accessing HE through widening participation initiatives, whose awareness of their structural disadvantage may lead to them considering themselves marginal, aspirations toward respectability via status or being "of value" may be understood as attempts to contest such marginality. This will be discussed later in greater detail. 


\section{To help the community}

A significant majority of students on the programme aspired to studying pharmacy, and orientated themselves toward this "imagined community". For these students in particular, "helping people" and "giving back to the community" emerged as a strong theme in stated motivations for entering HE:

'University degrees such as Pharmacy do not just transform your opportunities in life but also the lives of others in society.' (Student W)

'Gaining a paper that would forever hold my name isn't just about raising my credibility, but having the opportunity to impact, or even change others' lives.' (Student $\mathrm{Y}$ )

Having the ability to effect meaningful change, not only for themselves and their families, but for others in the community and beyond appeared as an important motivating factor for students whose own agency may have felt limited by the structural constraints of their current lived realities. Some students recognised that acquiring this capacity to effect such change would place them in a position of privilege, placing them under further obligation:

'...by getting a degree I will have acquired further opportunities in life that will determine my contribution to societies which may not have the same privileges or opportunities given to me.' (Student O)

A common narrative among aspirant pharmacy students was that of their "dream career" or "life's ambition", framing their career choice as a vocation.

'Overall getting a degree will allow me to peruse [sic] my life ambitions and try and make a difference in the world by grasping the knowledge being taught.' (Student P)

This orientation toward the "imagined community" of pharmacists emerged strongly through blog posts and Adobe Spark videos as well as questionnaires and interviews. The intensity of this identification with the (imagined) values and subject position of pharmacists appears to run counter to literature (e.g. Wayne et al. 2016) on student transitions which posits the sequential development of student identity, disciplinary identity, and then professional identity. For these students, it would appear, their strong orientation toward their "imagined community" served as the motivator for the development of student, and disciplinary, identities in a far more complex and interwoven manner.

\section{Spatial issues}

One spatially-related theme that emerged was the influence of role models from the (geographic or cultural) community who inspired some of the students to emulate their careers: 
“...Hearing stories about my English elderly neighbour's career as a pharmacist has motivated me to follow the same path as her. She has consistently encouraged me to go to university, and supports me throughout." (Student AA)

'... when I had worked with my Uncle who is a community pharmacist after my A levels, the satisfaction and content that was brought to my uncle's face when he was helping patients with medication inspired me to follow in his footsteps and be the reason behind many patients' smiles.' (Student $\mathrm{BB})$

For the latter student, whose lack of a career plan had led to her disengagement with her studies during A-levels and subsequent disappointing results, the exposure to the working environment within a pharmacy proved pivotal in motivating her career, and study, choice. Students like these are often cast in a "discourse of deficit" as lacking the capitals that are valued within higher education, yet these quotes demonstrate the value of the "community cultural capital" (Yosso 2005) they were able to mobilise.

Another spatially-related theme concerned commuting. Most of the students in this study were commuter students, living with their family of origin or with their partner and / or children. As described above, this brought with it numerous obligations at, and beyond, home; it also resulted in sometimes significant amounts of time being required to travel to and from the university daily.

'Travelling is something that has left me feeling exhausted every day, leaving me unable to revise, work and complete my tasks on time.' (Student EE)

'I commute to university. First I catch the bus to the train station and then the train to get to university which make it tiresome. Everyday 2-3 hours of my time is wasted because of this. Occasionally I will arrive late to University and so I will miss the lecture and class tutorials. After University when I get home I feel tired so I am not as focused...' (Student FF)

While some students reported being able to work during their commutes, for many this was not possible - if they were driving, or if travelling on crowded public transport.

Several students who lived at home also cited "independence", and the ability to "stand on their own feet", as a major motivation for embarking on university studies:

'[My main motivation for university is] to be successful and independent...

Being able to work and live independently.' (Student CC)

Some students cited this as a motivation that their parents shared, wishing to see their children succeed in their studies and become independent and 
self-reliant. In a few cases, this desire for independence led to students moving out of home and into student accommodation.

'My family live [locally] but I live in student accommodation because I want independence.' (Student D)

'[I've developed] more independence through living away [from home]' (Student A)

One student admitted to profound homesickness, it being her first time living away from home, but acknowledged that the experience had helped her to "grow up" and become more independent.

\section{Discussion}

For these students, the tension between the respect they described having for their parents and the lack of respect they observed being meted out to their parents as a result of perceived marginal status (due to factors including a lack of higher education, chronic physical or mental health problems, and low socio-economic status) motivated them to aspire to professional careers which offered the promise of greater material comfort and the opportunity to salve their parents material circumstances.

These students hoped that by assisting financially, they could address the difficult circumstances and affect the health, retirement prospects and general life chance outcomes for their parents, and their younger siblings and extended family - all of which was predicated on them securing "a stable job".

Beyond the future "stable job" these students envisaged that would allow them to lift themselves and their extended families out of their current circumstances, these students also identified current obligations toward their families to perform duties around or outside of the home. These obligations were often gendered, with more students identifying as female being required to take on cooking, cleaning and related duties, and to act as personal assistants to their mothers in running the household. Birth order was also significant, with older siblings being responsible for the supervision and care of younger siblings, nephews and nieces. Several students were responsible for the care of older family members such as grandparents, or for parents with chronic physical or mental health conditions.

Extended families who ran family businesses such as restaurants, pharmacies or newsagents often required students to assist after classes and over weekends, and a number of students reported having to maintain parttime employment in industries such as retail or catering to help their families financially. While these obligations were particularly pronounced among commuter students, even students living in student accommodation 
were not spared, with some still expected to help out remotely or by returning home outside of term-time or over weekends.

While "independence" was reported as being desirable to both students and their parents, it is unclear whether there was complete unanimity on what that might entail. For example, while parents reportedly readily embraced the notion of their children becoming financially self-sufficient, one student reported a "cultural barrier to moving away" from home, describing how her older, employed siblings continued to live at home and help out - despite having described her family's cultural orientation as "not traditional". For many students, though, the factors are not only cultural but economic. As Case et al. (2018:42) note,

'Of course, the decision to study from your home town or to go away is one with significant financial consequences. For many students it is simply not possible to find funding for food and accommodation outside of the home. If there is a university in your home town, then for many students this is the only option worthy of serious consideration.'

For students living at home with their families, this often presented a double-edged sword - they enjoyed the support of their families, and were spared the homesickness reported by students who lived away from home; but living at home in most cases presented a suite of duties and obligations (although, as noted earlier, living in student accommodation did not rule out continued obligations at home.)

These duties and obligations at home may conflict with the demands of students' studies: several students reported problems with "time management" relating to balancing the demands of their home lives with the demands of coursework, revision and other study-related deadlines. At source, this may constitute a fundamental clash of values, with higher education increasingly constructed as a "private good" (Case et al. 2018; see also discussion in Marginson 2011 for a broader consideration of this issue) and students constructed as individual agents; yet their kinship ties particularly for these commuter students - anchor them strongly in their families and communities and demand that the benefits accrue more broadly. While some students see the demands placed on them by extended family as constraining their ability to succeed in their studies, most of the students in the study framed their challenge as being one of "managing their time" between these competing demands, individualising the issue rather than acknowledging its broader structural character.

These familial obligations may be understood as a form of "kinship tax" (also known, in the South African context, as "Black tax" - see Magubane 2016). In its crudest form, it is the expectation of providing for the extended family (or kinship group, which may include individuals with strong social rather than purely blood ties) in return for the sacrifices made by the family (or community, or kinship group) in order to send the student to higher 
education. Hoff \& Sen (2016) argue that kinship tax can become a "poverty trap", with those individuals earmarked for "success" becoming so burdened by the obligations towards those who enabled their pathway to "success" that the benefits of success that accrue become too widely dispersed to raise either the individual, or their kinship group, out of circumstances from which the group sought to escape. In the case of these students, it is easy to conceive how that might play out - with students simply too burdened by demands of familial obligations, part-time work and commuting to muster the time, energy and "headspace" to devote themselves sufficiently to their studies to succeed academically.

This presents challenges to those teaching these students: attempts to "rightsize" family expectations by scheduling activities from 9am to $5 \mathrm{pm}$ during the first weeks of study do not seem to have sustainable effects in most cases, and are predicated on an assumption that family expectations can be "rightsized". Where students' demands on their time extend to parttime work which is necessary for survival, dependents such as children, and long commutes, there may be little flexibility. These attempts are also predicated on assumptions that students would opt to prioritise their studies over their familial demands and obligations: assumptions which are not always supported by evidence, particularly where students cite their families as their prime motivation for their studies.

While some students do position themselves strongly as individuals, many frame themselves within their broader family, extended family, or community context, as conveyed in their expressed motivations for embarking on higher education. This high degree of social consciousness, found largely within but not confined to students aspiring to be pharmacists and optometrists, runs counter to assertions such as those of Garibay (2015) who argue that STEM (science, technology, engineering and mathematics) students have less of an orientation toward social justice.

Wanting to help the community is also linked in some students' narratives to occupying a visible role within the community, and to status - relating to the issue of respectability. Respectability, according to Skeggs (1997) is a "key mechanism by which some groups are othered and pathologised". She notes (Skeggs 1997:1) that

'Respectability... would not be something to desire, to prove and to achieve, if it had not been seen to be a property of 'others', those who were valued and legitimated... It is rarely recognised as an issue by those who are positioned with it, who are normalised by it, and who do not have to prove it.'

It is thus not surprising that, in communities which may feel "othered" and marginalised (particularly in the current political climate, with students admitting to feeling upset or threatened by discourses of Islamophobia, xenophobia and intolerance), a desire for "respectability" and status should 
manifest. The classed, and raced, connotations of respectability may, similarly to the overt economic connotations of "a stable job", encode the aspirations of members of these communities to enjoy equal value in their societies.

Science was seen as indexical of this "respectability", particularly in communities with Asian roots, hence many students being encouraged by their families to embark on studies in this domain. A significant majority of students on the programme aspired to undergraduate studies in pharmacy or optometry - programmes with a clear vocational outcome. Such careers are not only inherently "respectable", but are also viewed as stable. This resonates with Case et al.'s (2018:49) assertion that

'...this distinction between having parents with strong views about subject choice or those who are quite laissez faire about what their children study seems related to the family's financial situation, on whether it can afford for a young person to follow a line of study that might not necessarily lead to a well-paying job.'

\section{Implications for practice:}

Teaching and learning practices in universities are still largely predicated on a model of direct transition, full-time students living among peers, unfettered by other obligations (such as employment, caring responsibilities or obligations to extended family networks). Where students have work, this is assumed to be discretionary (outside of formal placements or internships built into the structure of the programme) and thus to be of lower priority than their studies. Additionally, in the UK, undergraduate students are required to balance formal contact hours with independent study, fostering self-directed learning. This creates tensions for students whose time allocation may not be fully within their own discretion, or where choices may be overlaid with far greater signification: is the decision to spend the evening reading over the day's notes rather than helping out with younger siblings a move towards rejecting one's "culture"? Is opting to work in the family business rather than read potential sources for an upcoming assignment a signal that one isn't really that committed to one's studies, but merely using them to secure a better marriage?

Recognising, acknowledging and validating the context, experiences and "lifeload" of these students can engender rapport and facilitate persistence and success (Cree et al. 2016). While this recognition might lead to a bending of the rules for these students, Hinton-Smith (2012) argues that this should lead instead to a more responsive system for all students, and one that draws on the supportive role of ICT to aid flexibility. The volume of students in the study who cited the use of Lecture Capture technology as a critical resource in their studies supports this. 


\section{Conclusion}

Students in this study typically demonstrated a mix of "wideningparticipation" factors, with many being first-in-family commuter students from a range of backgrounds, and thus being "at risk" in several ways when considering differential outcomes. Analysing their stated motivations and aspirations for study reveals complex familial and social factors which enable and constrain their ability to engage with their studies, notably the duties and obligations towards their extended families that exist as a "kinship tax" and which threaten their ability to sustain sufficient time, energy and "headspace" to meet the demands of their studies. This presents challenges in teaching these students, whose priorities may not lie unambiguously with their studies, given their familial and social contexts. However, changing practices based on understanding the nuances of students' lives can help to mitigate structural constraints and challenge differential outcomes. 


\section{References}

Burke, P. J. (2012). The right to higher education: Beyond widening participation. London: Routledge.

Canning, A., Hume, S., Makinson, L., Koponen, M., Hall, K., \& Delargy, C. (2018). KCLXBIT project report 2015-2017: Behavioural insights in higher education. London: King's College.

Case, J., Marshall, D., McKenna, S., \& Mogashana, D. (2018). Going to university: The influence of higher education on the lives of young South Africans. Cape Town: African Minds.

Charmaz, K. (2014). Constructing grounded theory (2nd ed.). London: Sage.

Cotton, D. R. E., Joyner, M., George, R., \& Cotton, P. A. (2016). Understanding the gender and ethnicity attainment gap in UK higher education. Innovations in Education and Teaching International, 53(5), 475.

Cree, V., Christie, H., \& Tett, L. (2016). Relationships matter: The views of college entrants to an ancient scottish university. Scottish Educational Review, Retrieved from http://eprints.hud.ac.uk/29727/

Garibay, J. (2015). STEM students' social agency and views on working for social change: Are STEM disciplines developing socially and civically responsible students? Journal of Research in Science Teaching, , 610632.

Ghaffar, F., \& Stevenson, J. (2018). British Pakistani and Bangladeshi women, higher education and defensive othering. Widening Participation and Lifelong Learning, 20(3), 50-67. doi:10.5456/WPLL.20.3.50

Harvey, A. (2017). Should university funding be tied to student performance The Conversation, April(2)

Hinton-Smith, T. (Ed.). (2012). Widening participation in higher education: Casting the net wide?. Basingstoke: Palgrave Macmillan.

Hoff, K., \& Sen, A. (2006). The kin system as a poverty trap? In S. Bowles, S. N. Durlauf \& K. Hoff (Eds.), Poverty traps (pp. 95-115). Princeton: Princeton University Press.

Jones, S. (2018). Expectation vs experience: Might transition gaps predict undergraduate students' outcome gaps? Journal of further and Higher Education, 42(7), 908-921. doi:10.1080/0309877X.2017.1323195

Lehmann, W. (2009). Becoming middle class: How working-class university students draw and transgress moral class 
boundaries.Sociology, 43(4), 631-647.

doi:10.1177/0038038509105412

Magubane, N. N. (2016). Black tax: The emerging middle class reality. MBA thesis. University of Pretoria.

Marginson, S. (2011). Higher education and public good. Higher Education Quarterly, 65(4), 411-433. doi:10.1111/j.1468-2273.2011.00496.x

McDuff, N., Tatam, J., Beacock, O., \& Ross, F. (2018). Closing the attainment gap for students from black and minority ethnic backgrounds through institutional change. Widening Participation and Lifelong Learning, 20(1), 79-101. doi:10.5456/WPLL.20.1.79

Mowat, J. G. (2018). Closing the attainment gap - a realistic proposition or an elusive pipe-dream? Journal of Education Policy, 33(2), 299-321. doi:10.1080/02680939.2017.1352033

Neves, J. (2018). 2018 UK engagement survey. (). York: Advance HE.

Quinn, J. (2013). Drop-out and completion in higher education in Europe among students from under-represented groups. Brussels: European Union.

Skeggs, B. (1997). Formations of class and gender: Becoming respectable London:Sage Publications.

Smith, E. (2016). Can higher education compensate for society? Modelling the determinants of academic success at university. British Journal of Sociology of Education, 37(7), 970-992. doi:10.1080/01425692.2014.987728

Southall, J., Wason, H., \& Avery, B. (2016). The transition to higher education for non-traditional, commuter students - a synthesis of recent literature to enhance understanding of their needs Sheffield Hallam University. doi:10.7190/seej.v4i1.128

Tight, M. (2019). Student retention and engagement in higher education. Journal of further and Higher Education, , 1-16. doi:10.1080/0309877X.2019.1576860

Trowler, V. (2019). Transit and transition: Student identity and the contested landscape of higher education. In S. Habib, \& M. Ward (Eds.), Identities, youth and belonging (pp. 87-104). London: Palgrave Macmillan.

UUK, \& NUS. (2019). Black, Asian and minority ethnic student attainment at UK universities: \#CLOSINGTHEGAP. (). London: Universities UK and National Union of Students. 
Wayne, Y., Ingram, R., MacFarlane, K., Andrew, N., McAleavy, L., \& Whittaker, R. (2016). A lifecycle approach to students in transition in Scottish higher education. (). York: Higher Education Academy.

Yosso, T. J. (2005). Whose culture has capital? A critical race theory discussion of community cultural wealth. Race Ethnicity and Education, 8(1), 69-91. doi:10.1080/1361332052000341006 